\title{
Dubreuilh's melanosis or malignant lentigo
}

\section{Olfa El Amine El Hadj, Leila Bouhajja, Aida Goucha, Wafa Rekik, Ahmed El May, Amor Gamoudi}

Department of Pathology, Carcinological Institute Salah Azaiez, Tunis, Tunisia

Corresponding author: Dr. Olfa El Amine El Hadj, E-mail: olfaelamine@yahoo.fr

Sir,

We report a 69 year-old man who presented with a 5 -year history of pigmented lesion on the tip of the nose. Physical examination revealed a $2 \mathrm{~cm}$, hyperpigmented lesion of the nose. The cervical and abdominal ultrasonographies were normal. A surgical resection of the tumor was performed. Grossly, the tumor was flat, black or dark brown, and measured $1.5 \mathrm{~cm}$ of diameter. Histological examination showed a confluent growth of melanocytes along dermo-epidermal junction with involvement of adnexal structures (Fig. 1). Some isolated or nested cells infiltrated papillary dermis and were surrounded by inflammatory and fibrous stroma (Fig. 2). The derm presented a significant solar elastosis and the epidermis was atrophic. These features confirmed the diagnosis of Dubreuilh's melanosis. At 3 years of follow-up, the patient was asymptomatic and there was no recurrence.

The patient's informed consent was obtained.

Prior to the study, patient gave written consent to the examination and biopsy after having been informed about the procedure.

Lentigo maligna (LM) is a premalignant melanocytic neoplasm occurring on the sun-exposed skin of the old patient (>60 ans) [1]. It's a subtype of melanoma in situ, and it has a female preponderance. Lentigo maligna melanoma (LMM) is one of the four main subtypes of invasive melanoma and represents $5-15 \%$ of cases [2]. Clinically, it's a pigmented macula that is dark brown, tan, or black, located on the face or on the scalp [3]. The clinical differential diagnoses are a simple solar lentigo, a pigmented actinic keratosis and

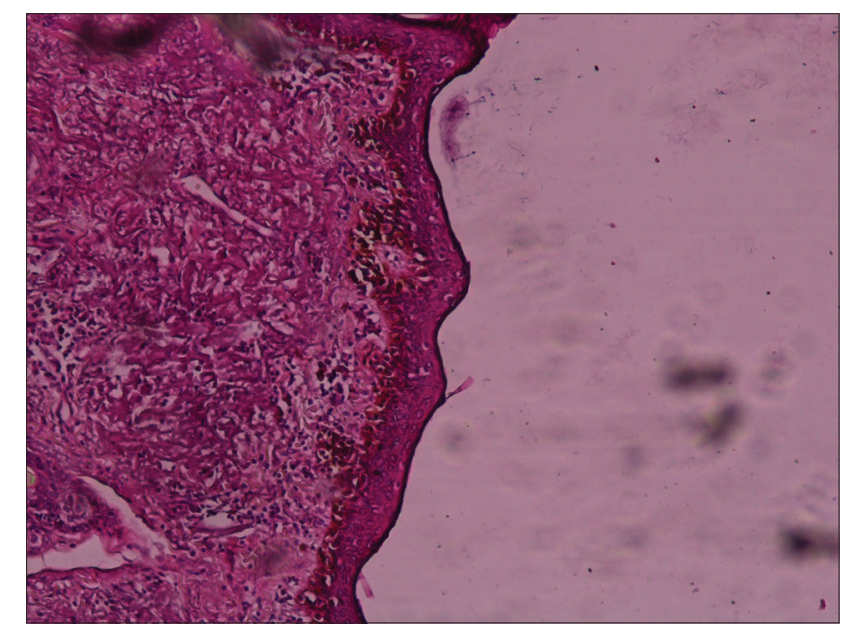

Figure 1: Confluent growth of melanocytes along dermo-epidermal junction with involvement of adnexal structures.

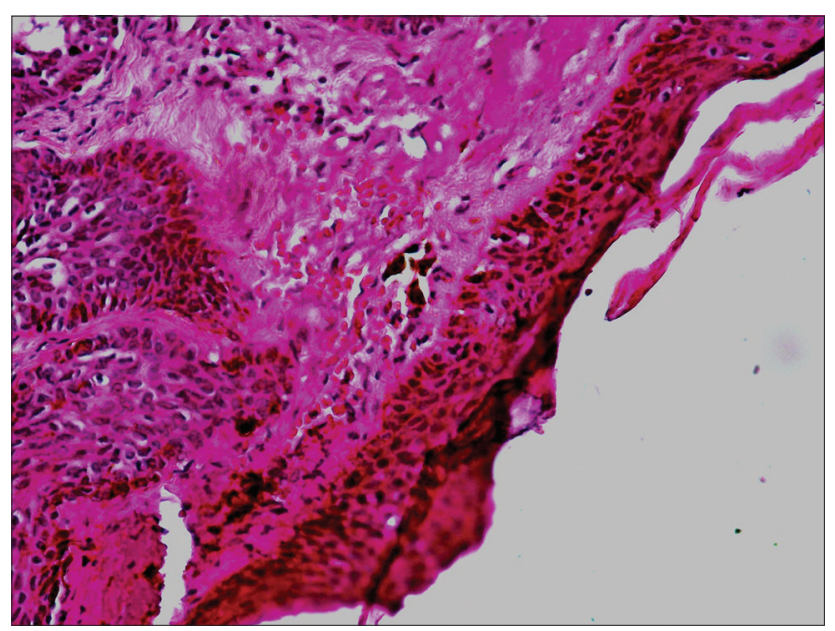

Figure 2: Some isolated or nested cells infiltrated papillary dermis and were surrounded by inflammatory and fibrous stroma.

seborrheic keratosis. Histological image of LM is that of a melanoma in situ. LMM shows a dermal infiltrate 
of atypical melanocytes [4]. Immunohistochemistry, the melanocytes are positive for Melan-A antigen and HMB45. Furthermore, epidemiological and molecular studies differentiate two lanes of carcinogenesis for melanoma: A way for the young adults, with many nevi and having an intense and intermittent sun exposure, and a second, like the LMM, older individuals who are chronically exposed to sun. Molecular analyzes seem to support this duality by highlighting the BRAF mutations in the first group melanoma [5]. Surgical excision is the treatment of choice to obtain clinical and histologic clearance. The recurrence rate after micrographic surgery is about $4-5 \%$ and 7-10\% after conventional surgery (cryotherapy and radiotherapy) [1]. A 5 millimeter cutaneous margin must be resected around this lesion. LM prognosis is excellent as an in situ (100\%) but LMM prognosis depends on tumor thickness (Breslow index).

\section{CONCLUSION}

LM and LMM differ from other types of melanoma, by their clinical, histological features, carcinogenesis, evolution and require appropriate care.

\section{Consent}

The examination of the patient was conducted according to the Declaration of Helsinki principles. Written informed consent was obtained from the patient for publication of this article.

\section{REFERENCES}

1. Stevenson O, Ahmed I. Lentigo maligna: Prognosis and treatment options. Am J Clin Dermatol. 2005;6:151-64.

2. Liu V, Mihm MC. Pathology of malignant melanoma. Surg Clin North Am. 2003;83:31-60.

3. Rigual NR, Popat SR, Jayaprakash V, Jaggernauth W, Wong M. Cutaneous head and neck melanoma: the old and the new. Expert Rev Anticancer Ther. 2008;8:403-12.

4. Le Gal F-A, Toutous-Trellu L, Kaya G, Salomon D. Lentigo maligna: un mélanome particulier. Rev Med Suisse. 2011;7:765-71.

5. Thomas NE, Edmiston SN, Alexander A, Millikan RC, Groben PA, $\mathrm{Hao} \mathrm{H}$, et al. Number of nevi and early-life ambient UV exposure are associated with BRAF-mutant melanoma. Cancer Epidemiol Biomarkers Prev. 2007;16:991-7.

Copyright by Olfa El Amine El Hadj, et al. This is an open access article distributed under the terms of the Creative Commons Attribution License, which permits unrestricted use, distribution, and reproduction in any medium, provided the original author and source are credited

Source of Support: Nil, Conflict of Interest: None declared. 